\title{
Trajetória artística de Alphonsus Benetti ${ }^{1}$
}

Luana de Siqueira Brasil ${ }^{2}$

Ayrton Dutra Corrêa ${ }^{3}$

\section{Resumo}

Com a presente investigação pretende-se conhecer e divulgar a trajetória artística de Alfonso Benetti, pintor conhecido nacional e internacionalmente pela sua produção de grande porte na esfera da pintura. O referido artista é Coordenador de um dos ateliês de pintura do Centro de Artes e Letras da Universidade Federal de Santa Maria - RS. Sua construção é intensa e constante, trabalhando a figura feminina nas mais variadas possibilidades representacionais. Embora tenha explorado as linguagens do desenho e da xilogravura sua opção foi decisiva pela pintura.

Palavras-chave: Trajetória artística; pintura; investigação.

\begin{abstract}
The following study aims at knowing and telling about Alphonsus Benetti's artistic trajectory, a nationally as well as internationally well-known painter. He is known by his big size production in painting. The referred artist is the Coordinator of a painting atelier at the Center of Arts and Letters at the Federal University of Santa Maria - RS. His work is intense and constant. He features the feminine figure in the most varied possibilities. Although he has explored the several forms of drawing and xylograph his option was for the painting.
\end{abstract}

Key-words: Artistic trajectory; painting; investigation.

\section{1-Introdução}

Trajetória da carreira artística é uma das formas de se conhecer e divulgar a produção desenvolvida por um artista plástico ao longo de seu transcurso vivencial. O presente trabalho tem como meta básica apresentar resultados finais da pesquisa que foi desenvolvida a partir da construção da História de Vida do pintor Alphonsus Benetti.

Este registro alcança uma memória pessoal que é também uma memória social, familiar e grupal (BOSI, 1994, p.37). Assim, ao acionar a memória, as lembranças fluem naturalmente bem como a identidade de cada indivíduo. Neste sentido a questão da identidade do artista como um ser produzido historicamente, ou seja, essencialmente social, vem ao encontro das relações entre identidade (o indivíduo como pessoa),

\footnotetext{
${ }^{1}$ Pesquisa realizada com financiamento PIBIC/CNPq

2 Acadêmica do curso de Artes Visuais- Bacharelado da Universidade Federal de Santa Maria. Bolsista PIBIC/CNPq do Projeto "Trajetória Artística de Alphonsus Benetti", durante o período de agosto de 2007 a julho de 2009.

${ }^{3}$ Professor PhD do Centro de Artes e Letras da Universidade Federal de Santa Maria - RS. Atua como docente e orientador, no Programa de Pós-Graduação em Artes Visuais - PPGART, linha de pesquisa Arte e Visualidade e no Programa de Pós-Graduação em Educação, linha de Pesquisa Educação e Artes.
} 
processo (direcionamento em sua construção artística) e metamorfose (transformações ocorridas durante sua trajetória).

A identidade como está sendo pontuada relaciona-se com as características ou traços de personalidade que o indivíduo deixa transparecer intencionalmente, ou involuntariamente em sua obra de arte. Assim as representações sociais que o artista tem de sua visão de mundo vêm ao encontro da personalidade do ser que produz arte.

A representação não é uma simples duplicação mental ou simbólica da identidade, é o resultado de uma articulação entre identidade pressuposta (derivada, por exemplo, do papel social), da ação do indivíduo e das relações nas quais está envolvido concretamente (JAQUES, 1998). Esse envolvimento do artista nas relações sociais concretas em que se envolve propicia o acesso à produção da cultura e a relação desta produção com os significados valorizados socialmente.

O fazer artístico se instaura neste contexto, como uma forma de criar, ordenar, configurar, articular e expressar uma dada realidade. Nessa experiência estão implícitas as configurações de vida dos indivíduos-artistas, pautadas em valores coletivos e individuais, expressando-se a partir de uma materialidade própria (CORRÊA, 2000).

"A arte é a expressão de um sentir particular, externado por diferentes linguagens, decorrentes do simples fato de estarmos vivos, percebermos o que nos inquieta" (PEREIRA, 1993, p.91).

Considerando-se o artista que se envolve neste fazer investigativo, tem-se claro que neste tipo de pesquisa o indivíduo é visto como o sujeito de sua própria vida e conseqüentemente do processo do qual é um dos atores, portanto, o Eu Pessoal e o Profissional são indissociáveis.

Nesta dimensão o artista plástico como pessoa é considerado em uma visão holística, um ser que se constrói através das relações inter-humanas e culturais. O indivíduo-artista como ser sócio-cultural e histórico tem sua relação direta com a identidade, em que o artista como pessoa, constrói suas relações nas repercussões da sociedade que se concretizam como ator social, pois esta identidade se molda e é mediada através das relações sociais. A identidade como está sendo pontuada se relaciona com as características ou traços de personalidade que o indivíduo deixa transparecer, tanto de maneira voluntária como involuntária em sua obra de arte. As representações sociais 
que o artista tem de sua visão de mundo vêm ao encontro da personalidade do ser que produz arte.

Com referência ao artista como pessoa, ou seja, um indivíduo pertencente ao universo sócio-cultural, e vai procurando entender a dinâmica humana no entre-jogo do eu individual e do eu coletivo. Assim sendo, "a vida de um artista está inteiramente debruçada sobre a arte, inteiramente posta sob sua insígnia" (PAREYSON, 1997, p. 91), pois a personalidade artística e a humana estão literalmente inter-relacionadas.

Neste sentido o indivíduo-artista busca captar e configurar as realidades que o rodeiam, na tentativa de uma compreensão de vida, de si próprio e do mundo. Assim, entendemos o processo de criação e as potencialidades criativas como inerentes e necessárias às atividades humanas, as quais se circunscrevem nas diferentes dimensões da vida.

Assim, na vida de um artista plástico com um universo rico e complexo e muitas vezes até contraditório no que concerne aos valores estabelecidos pela sociedade, este é envolvido em uma lógica dialética, na qual, eventos concretos da vida dos indivíduos e da sociedade são vistos como interdependentes, em um permanente intercâmbio transformacional. Logo, ainda que constituídas de ordenações específicas, dentro de uma materialidade própria, as propostas de linguagem visual, sobretudo a pintura que é a linguagem predominante na produção de Alphonsus Benetti, e, suas relações como artista/professor com o ensino de artes envolvem e refletem toda uma atividade humana inserida em uma realidade social. Independente da questão contextual onde o indivíduo atua, hoje, a reflexão sobre a contemporaneidade artística nos conduz a crer que essa vive uma profunda indefinição, inclusive no que se refere ao seu valor social.

Cientes de que o homem é produto de sua época, desdobrando o seu ser social em formas culturais, consideramos que nessa interação/ação com o mundo, o indivíduoartista descobre novas qualidades reconsiderando, até mesmo, valores culturais.

\section{2 - Aspectos Metodológicos}

Assim posto resumidamente a temática básica da investigação, os objetivos previstos estão sendo alcançados, quais sejam: a) através da reflexão em torno das particularidades e especificidades que envolvem o participante da pesquisa, construir a historicidade artística do artista em pauta; b) verificar se o artista utiliza ou utilizou diferentes linguagens ao longo de sua carreira e qual a repercussão sobre sua produção atual. 
Levando em consideração os aspectos colocados para este fazer investigativo, optou-se por um Estudo de Caso Etnográfico de natureza qualitativa de cunho interpretativo e descritivo. Tal escolha prende-se ao fato de o centro de interesse do trabalho voltar-se para a construção de significados elaborados pelo participante.

Um dos aspectos de extrema relevância na abordagem escolhida para este fazer investigativo está no conhecimento mais próximo ao mundo da vida e da realidade contextual de um artista plástico. Neste sentido, tem-se a possibilidade de um novo tipo de conhecimento sobre o sujeito da investigação, mais adequada para compreendê-lo como pessoa e profissional, bem como toda a evolução das obras realizadas em diferentes momentos da carreira.

Os métodos utilizados na coleta de dados e que deu origem à História de Vida Artística de Alphonsus Benetti foi a Entrevista em Profundidade, onde a narratividade,

designa la cualidad estructurada de la experiencia vista como relato; por otro lado las pautas/formas de construir sentido, a partir de hechos temporales, por medio de la descripción y análisis de hechos temporales personales, por medio de la descripción y análisis de los datos (BOLÍVAR et alii, 2001, p.17).

Após entrevistas no ateliê do artista a respeito de sua trajetória a pesquisa foi finalizada envolvendo a análise das imagens e narrativas produzidas a respeito das fases de produção. Inicialmente a linguagem do Desenho foi bastante forte, porém a pintura se tornou predominante para o artista.

\section{3 - Revisitando alguns dados biográficos do artista}

Alfonso Benetti é natural de Faxinal do Soturno- RS, mais especificamente nascido em 1953, numa localidade de zona rural denominada Saxônia. Em sua vida acadêmica formou-se em Licenciatura em Educação Artística, posteriormente Bacharelado em Pintura na Universidade Federal de Santa Maria - RS. Realizou Mestrado em Educação, onde construiu sua dissertação envolvendo a temática Pedagogia da Pintura, trabalho este desenvolvido na abordagem da Etnografia Escolar, utilizando Estudo de Caso que ocorreu no atelier que é coordenador. Professor Adjunto IV do Departamento de Artes Visuais, ocupa o cargo de Chefe deste departamento e Coordenador do Curso de Desenho e Plástica por mais de uma gestão respectivamente. Ainda continua fazendo parte da gestão do curso citado como Vice-Coordenador. Coordenador do Atelier de Pintura 1336 do Centro de Artes e Letras da Universidade Federal de Santa Maria. 
Durante sua trajetória profissional, sua produção artística tem sido intensa, tendo realizado exposições individuais em inúmeras cidades brasileiras e também no exterior. Além da pintura, trabalhou também com xilogravura e desenho, porém sua grande paixão sempre foi a obra pictórica. Independente destas atividades possui muitos artigos publicados bem como capítulos de livros, sempre tendo como foco epistemológico, a pintura.

\section{4 - Imagens da trajetória artística}

Neste item são apresentadas algumas imagens, das mais de duzentas obras de arte que foram registradas no ateliê de Alphonsus Benetti, produzidas ao longo de sua carreira artística.

\section{1 - Desenhos}

Apesar de Alphonsus ter desde o início uma intenção bastante definida de fazer pintura, o desenho abre as portas de seu percurso artístico. Sendo ele seu primeiro elo de contato com o público, com trabalhos mandados para amostras, exposições e salões. Pois o desenho tinha uma presença muito forte naquele momento, inclusive como expressão e repercussão nacional de alguns artistas que estavam ali, como Carriconde, Quaglia e Amoretti. O desenho abaixo foi premiado no Salão de Artes Plásticas de Alegrete, onde o artista utilizou uma técnica mista (grafite e ecoline sobre papel) para sua elaboração.

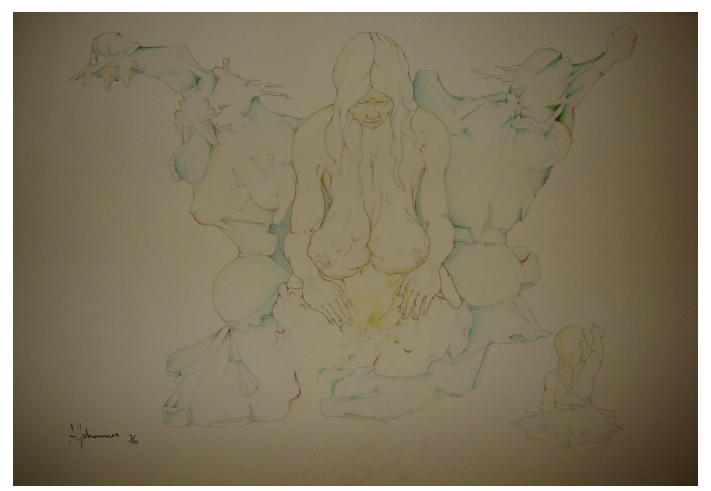

Figura.01 $(34,5 \times 51 \mathrm{~cm}, 1976)$

A seguir, um desenho realizado em aula, durante a graduação no Curso de Artes, onde trabalhava as formas de maneira mais figurativa. O trabalho participou da exposição realizada na Galeria Studios em Porto Alegre em 1998. Consolidando seu compromisso, de produzir, e apresentar uma regularidade em mostrar seu trabalho ao público. E 
iniciando um compromisso com as pessoas que vêem suas obras e seguem acompanhando seu trabalho.

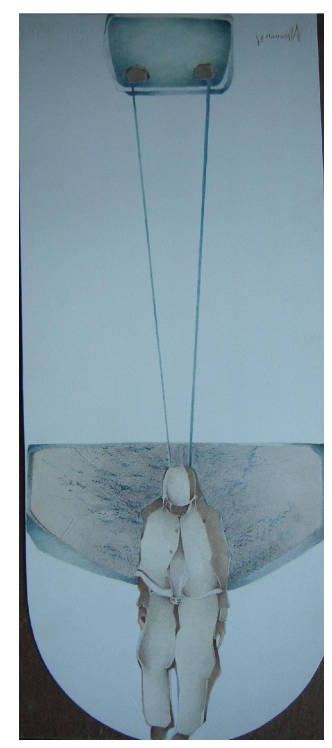

Figura.02 (55x22,5cm, 1977)

\section{2 - Pinturas}

Pinturas realizadas durante o Curso de Artes. Nesta fase inicial, utiliza uma paleta de cores primárias. Alphonsus buscava uma experiência com colagens. Analisando a seqüência de imagens apresentadas notamos que possuem as mesmas tonalidades, apesar de cada pintura ter seu próprio ambiente e composição.

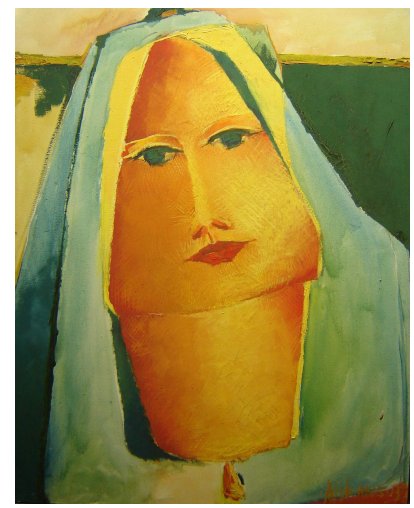

\section{Figura.03 $(55 \times 45,5 \mathrm{~cm}, 1977)$}

Ao longo do percurso do artista vemos acréscimos de mais elementos em suas pinturas, como, por exemplo, sua série chamada de "Mãe e Filho", que tem certa intencionalidade em representar uma relação mais íntima do artista com as figuras pintadas. E que, 
plasticamente, em termos de um trabalho plástico expressivo na pintura, também trazia repercussões em termos composicionais, fazendo variações, desde pequenos estudos, desenhos e colagem. Não é gratuita a presença de mais de uma figura, pois hoje Alphonsus não consegue desvincular a série de uma relação com a família, pois na época já constituía uma família, com esposa e dois filhos. É uma série que durou um bom tempo, cerca de 8 a 10 anos.

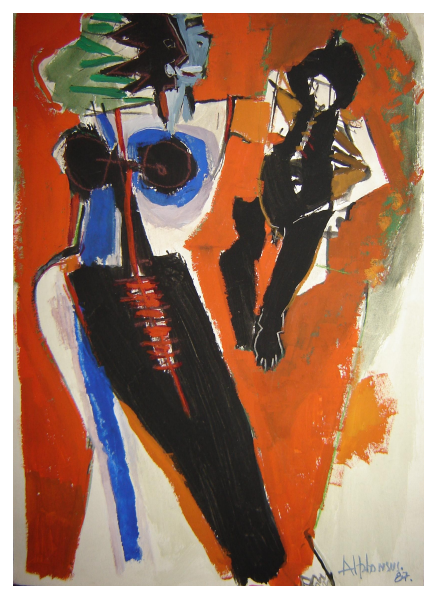

Figura.04 (35,3×24cm, 1987)

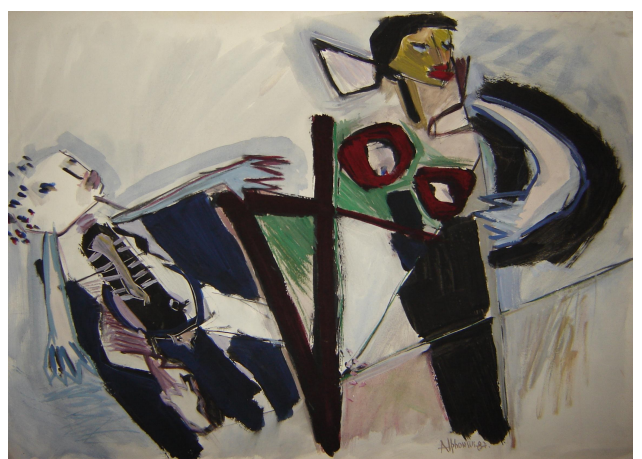

Figura.05 $(35 \times 50 \mathrm{~cm}, 1987)$

Nas obras seguintes aparecem formas que se repetem na construção da figura feminina são variações e estudos de um mesmo símbolo, buscando outras composições, como as formas da cabeça, seios e tronco. Esses signos, como Alphonsus denomina essas formas, não possuem um significado determinado, eles servem como apoio para uma pesquisa plástica, de composição e cor. 


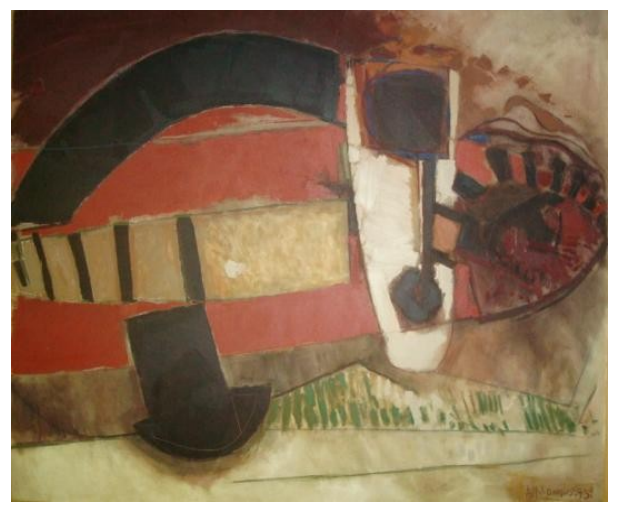

Figura.06 (120X145cm, 1995)

Por trabalhar muito tempo com desenho, vemos claramente em suas pinturas uma influência muito forte dessa linguagem, tanto nas construções das composições ou nas superfícies de tinta. Trabalha com formas, linhas e manchas, para dar um contraponto com o restante da obra. As massas de tintas, misturadas com areia ou gesso, ganham força em seu trabalho, percebemos a textura como algo mais tátil do que visual. Há um convívio diferente entre áreas planas, trabalhadas ora com rodo ou com espátulas, misturadas a áreas aquareladas e texturizadas também com o pincel. As obras tornam-se mais expressivas, a textura se torna um elemento importante para a obra.

Desconstrói muito as figuras em certos momentos, são determinados poucos elementos, como a cabeça, seios e coluna. Fazendo muitas variações de tamanhos de suportes, mas sempre modificando o tamanho em relação aos grupos.

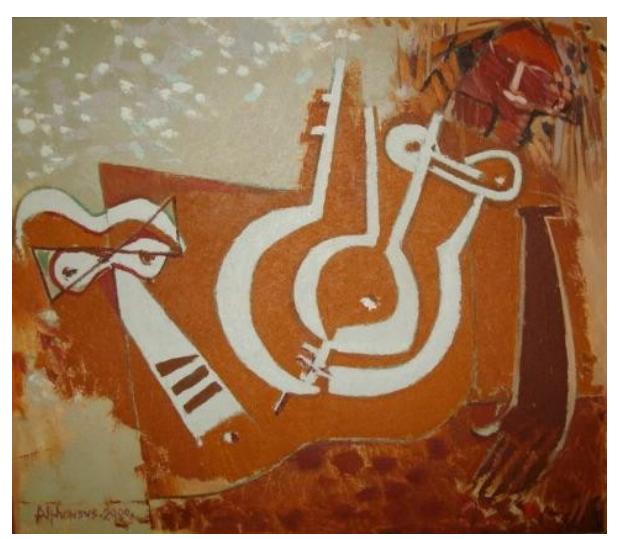

Figura.07 (85X95cm, 2000) 


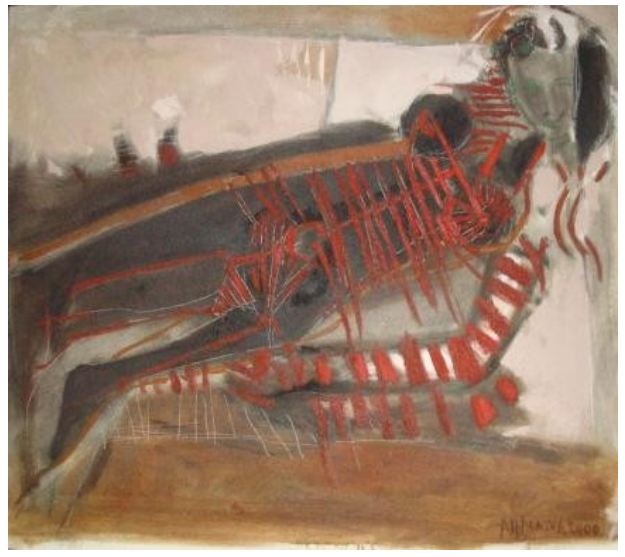

Figura.08 $(85 \times 95 \mathrm{~cm}, 2000)$

Algumas obras da série "O lugar dos Arcos" foram expostas na AB Galeria de Arte em Santa Maria, sendo consideradas pelo artista as mais maduras de sua carreira, na época. Alphonsus explica que o tema da exposição é transitar em outros sentidos e não ficar no lado formal do arco. A seguir imagens de obras que deram continuação a série nos anos posteriores a exposição.

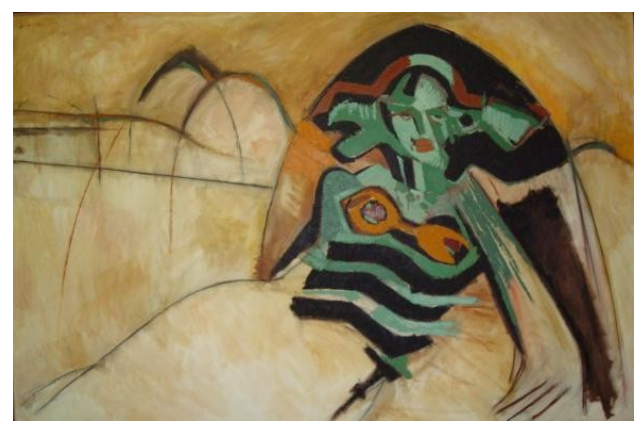

Figura.09 (120x180cm, 2001)

Título: "Passagem de Outono ou A Dama dos Pequenos Portais"

Desde 1977, Alphonsus trabalha com a imagem feminina e sempre conseguiu com êxito pesquisar o mesmo tema, atingindo resultados diferentes em cada uma de suas pinturas. Ele considera uma questão de desafio da modernidade, que seria trabalhar com a figura feminina, que muitos artistas já o fizeram e ainda assim, conseguir infinitas variações.

A série "Anche lui va a Ornesa" é uma homenagem às histórias e pessoas que guarda nas lembranças de infância, que teve ao lado de seu pai trabalhando na roça. Ornesa refere-se a um pequeno vilarejo do interior da Quarta Colônia de Imigração Italiana, chamada Val Veronês. É a primeira vez que se detém a um tema tão particular.

Nesta série entendemos a importância da textura nas pinturas de Alphonsus, onde ela se torna um dos fatores fundamentais para a expressividade de suas obras. 


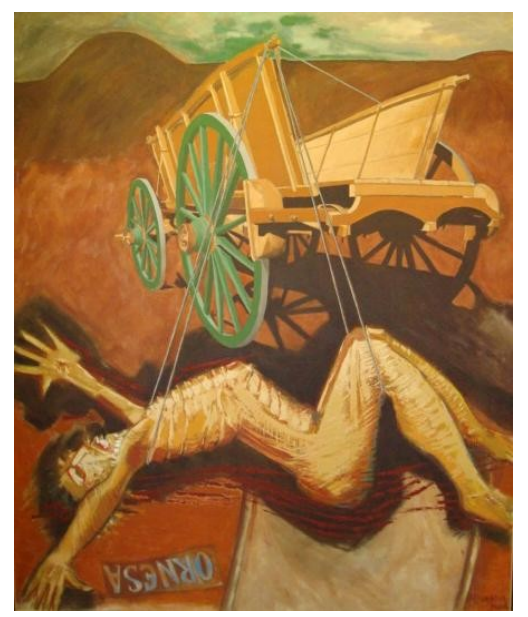

Figura.11 (145x120cm, 2004)

Título: "Deposizione: Sollevato per il trasporto"

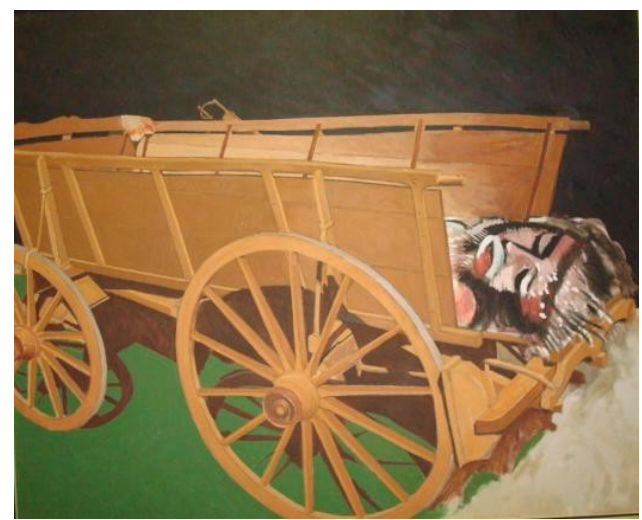

Figuras.12 (120x145cm, 2005)

Título: "Trasporto in carro da Buoi"

Suas obras a cada dia estão sofrendo modificações consideráveis nos últimos tempos, principalmente em relação à cor sua paleta de tons terrosos e escuros estão dando lugar a cores mais vivas e intensas. As figuras estão sofrendo modificações em sua composição, e estão aos poucos ficando com uma abordagem mais figurativa e erótica.

Sempre com êxito em suas pesquisas plásticas e pictóricas, o artista reelabora temas e os insere numa nova atmosfera e contexto. Lançando-os e alinhavando-os na contemporaneidade. Como as obras com teor mais erótico que trabalha atualmente, mexendo na composição das figuras de outra forma, com algumas modificações de espaço, e inserção de alguns elementos retirados de obras anteriores, mas reelaborandoos de maneira diferente. Procura sempre soluções e alternativas diferenciadas dentro de um percurso, mas sempre engajado e encadeado. Como as pinturas mostradas em suas 
duas últimas exposições, na Cláudio Carriconde, no hall do Centro de Artes e Letras (CAL), campus da UFSM e na APUSM, a série chamada "Musas Inquietantes- Revisitando $1994^{\prime \prime}$.

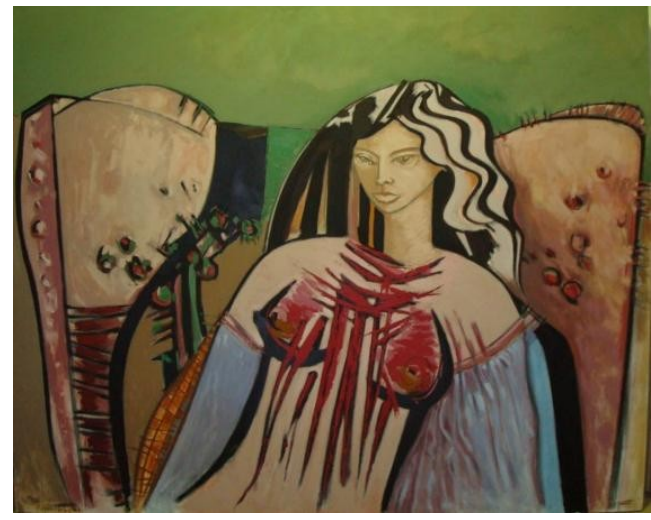

Figura.13 $(145 \times 180 \mathrm{~cm}, 2006)$

Título: "A nova Medéia ('La nuova Medea')"

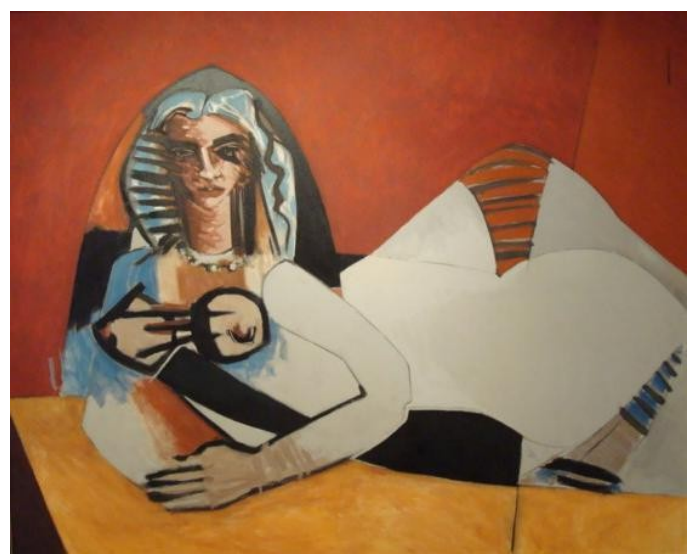

Figura.14 (145x180cm, 2008)

Título: "O Silêncio de Cassandra"

Para Alphonsus a questão da arte, da pintura, sempre foi um compromisso ético, independente da repercussão do seu trabalho. Para ele é importante continuar fazendo o que gosta e o que acredita. E por esta razão devemos continuar produzindo discursos sobre arte, porque é importante para a própria reflexão e também ter artistas produzindo obras que vão servir de referencial para essas reflexões em arte. 


\section{Considerações Finais}

Levando-se em consideração que a pesquisa está concluída, foram apresentadas algumas imagens e dados da produção do artista ao longo da carreira, ou seja: desenhos e pinturas. O valor estético das obras de Alphonsus é de extremo significado, pois se trata de um estilo pessoal onde a individualidade e a identidade está sempre presente. A metamorfose que o artista passou foi o foco de análise para a escrita final. o que apresentamos neste artigo é um recorte da pesquisa realizada.

\section{Referências}

BOLIVAR, A.; DOMINGO, J.; FERNANDEZ, M. La investigación biográfico-narrativa en educación: enfoque y metodología. Madrid: Editorial La Muralla, 2001.

BOSI, E. Memória e Sociedade. São Paulo: Cia. Das Letras,1994.

CORRÊA, H. Artista e Professor de Artes Plásticas: interpenetrações possíveis no Ensino da Arte. Dissertação (Mestrado em educação) - Universidade Federal de Santa Maria, Santa Maria, 2000.

JAQUES, M. C. et al. Psicologia Social Contemporânea. Petrópolis: Vozes, 1998.

PAREYSON, L. Os problemas da estética. São Paulo: Martins Fontes, 1997.

PEREIRA, L. H. M. Arte, fotografia em um tempo angustiado. O Ensino das artes nas universidades. São Paulo: Edusp, 1993. 